\title{
26. Palaeomagnetism and Palaeoclimatology of the Japanese Islands
}

\author{
By Masao Minato and Yoshiki Fujiwara
}

Department of Geology and Mineralogy, Hokkaido University, Sapporo

(Comm. by Hisakatsu YABE, M.J.A., Feb. 12, 1964)

Palaeomagnetic properties of the Japanese Neogene Tertiary and Quaternary rocks have been fairly well studied by many geophisicists up to the present. On the contrary, palaeomagnetism on the Palaeozoic, Mesozoic and Palaeogene rocks is still awaiting further detailed studies in the future, before we can state something definite about the palaeogeography or palaeoclimatology of the Japanese Islands through geological ages, based on palaeomagnetic studies.

Nevertheless, certain data hitherto obtained in this field in Japan, such as the virtual position of geomagnetic north pole for instance, can be now compiled as diagramatically shown in the map (Fig. 1).

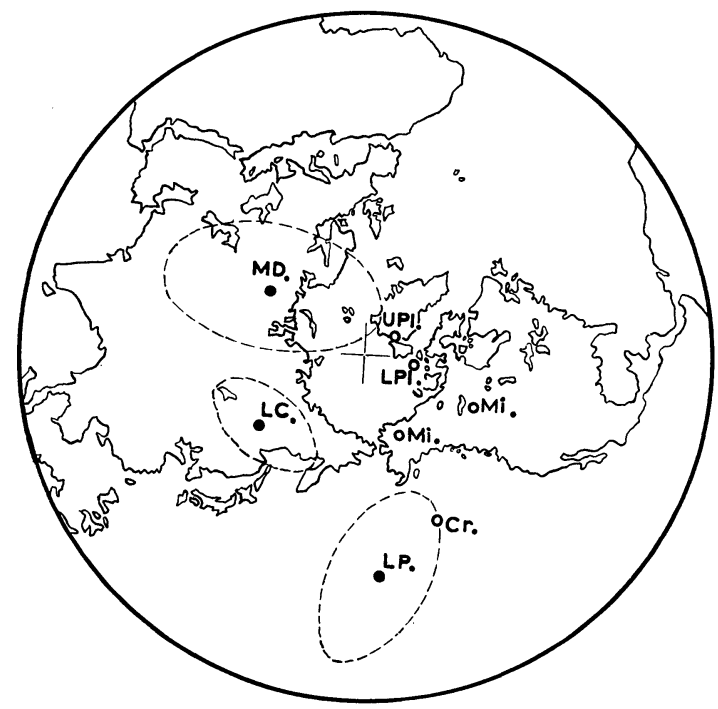

Fig. 1. Position of the geomagnetic north pole, based on the data on palaeomagnetism of Japanese rocks. MD: Middle Devonian, LC: Lower Carboniferous (Upper Tournaisian), LP: Lower Permian, Cr: Cretaceous, Mi: Miocene, LPl: Lower Pliocene, UPl: Upper Pliocene, Black circle: based on our data, white circle: after Nagata et al.; dotted line means the curve of reliability around each virtual geomagnetic north pole, according to the palaeomagnetic measurements.

The position of geomagnetic north pole in the Middle Devinian, Lower Carboniferous (Upper Tournaisian) and Lower Permian deter- 
mined on the basis of basic volcanic rocks found in the Nakazato series, the Arisu-, Ohdaira-series and the Sakamoto-sawa series respectively in the Kitakami mountains (M. Minato and Y. Fujiwara, 1963) can be shown in Fig. 1. The data concerning the geomagnetic north pole from the Cretaceous age to the Recent, which were compiled by Nagata et al. (1959), based on the palaeomagnetism of the Japanese rocks, can be plotted in the same figure. At present, we do not have any available data on the palaeomagnetic properties of the Silurian, Lower Devonian, Triassic and Jurassic rocks developed in Japan.

The result of the compilation above stated may suggest that polar wandering might have really occurred in the past. However, if we compare the virtual geomagnetic north pole for each geological age determined by us in Japan, to that determined by foreign scientists on the basis of rocks developed in the other continents, the assumption seems to be no more tenable that the Japanese Islands have been fixed in the same geographical position as at the present. In this connection Fig. 2 may serve as a good reference in which the Permian geomagnetic north pole locations ascribed by the Permian rocks collected from various parts of the world are extensively scattered without any apparent regularity.

Thus, the Japanese Islands are now considered to have certainly

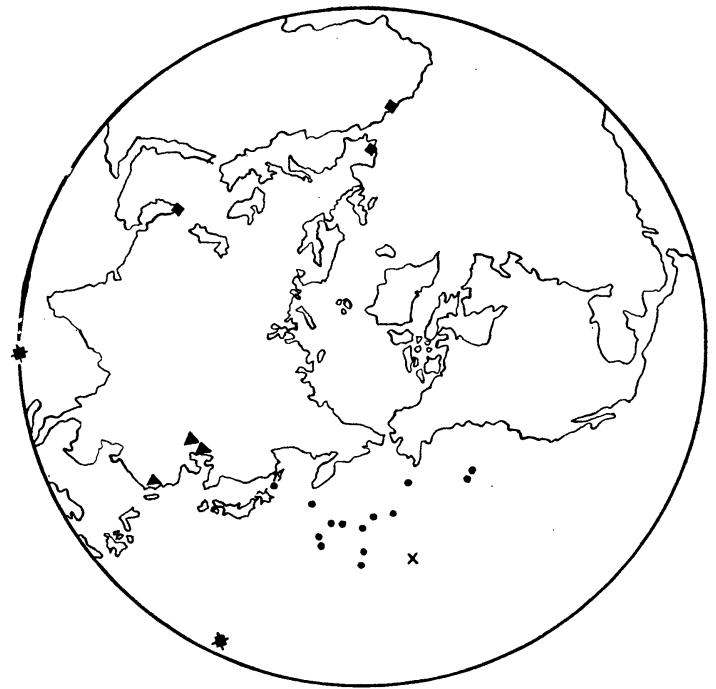

Fig. 2. Positions of Permian geomagnetic pole on the northern hemispher (after G. E. L. Dietzel in combination with the Japanese datum by Minato and Fujiwara). Black circle: inferred European rocks, black triangle: from North America (Arizona); black quadrangle: from Australian (New South Wales) rocks, black quadrangle plus cross: from African (Kenya) rocks and cross from Japanese (Kitakami) rocks. 
drifted to some extent in the past like the other continents. Namely, the Japanese Islands might have been situated in the Middle Devonian to the northwest of the present position, and then possibly moved gradually towards the south and east until the Permian. It may be perhaps the age ranging from the Later Viséan to the Early Permian, when the Japanese Islands were located in the most southward position of any time in the geological ages. This was also the time, when the sea of an east-west trend, viz. the tropical Tethys sea covered the entire Japanese Islands. In the next, the Japanese Islands seem to have moved in turn gradually towards the northwest through the Mesozoic and Cenozoic ages.

Such an assumption on drifting of the Japanese Islands can be regarded to correspond roughly to the change of palaeoclimatology of the Japanese Islands which is inferred by many data on the faunal and floral changes. Fig. 3 diagramatically shows how the change of palaeoclimatology can be correlated with the virtual change of latitude of the Japanese Islands through the geological ages.

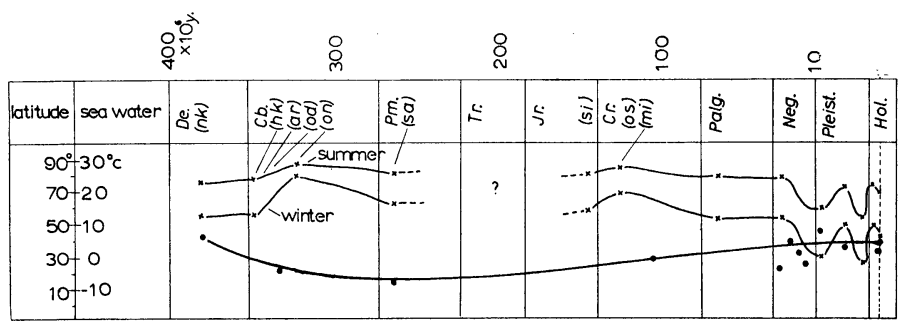

Fig. 3. Change of latitude and sea water in the Northeast Honshu including the Kitakami mountains through geological ages. De: Devonian, (nk): Nakazato stage; $\mathrm{Cb}$ : Carboniferous, (hk): Hikoroichi stage, (ar): Arisu stage, (od): Ohdaira stage, (on): Onimaru stage; Pm: Permian, (sa): Sakamotosawa stage, Tr: Triassic; Jr: Jurassic; (si): Shishiori stage; Cr: Cretaceous, (os): Ohshima stage, (mi): Miyako stage; Palg: Palaeogene; Neg: Neogene; Pleist: Pleistocene; Hol: Holocene.

A climatic curve is reproduced here from the former compilation by Minato (in S. Mori, 1961), in which he once tried to reconstruct the changing of temperature of sea water from the Devonian to the Recent, based on the palaeoecological data of the geological formations, chiefly developed in the Kitakami mountains, NE. Honshu.

Especially, amongst the Devonian, Carboniferous and Permian formations in the Kitakami mountains, corals, particularly composite forms and solitary forms of large size are especially abundantly found in the Onimaru series, Upper Viséan in age, as is once stated by $\mathrm{H}$. Yabe (1932); while corals decrease both in species and number in the next formation, viz. in the Nagaiwa series, presumably Namurian and 
Lower Westfalian in age.

In the Lower Permian, corals seem to have been not particularly flourishing in the Kitakami mountains, but a certain amount of fusulinid fauna may have taken their place. In any event, the age ranging from the Upper Viséan to the Lower half of the Permian, may have been the optimum for such tropical inhabitants as corals and fusulinids throughout the ages from the Devonian to the Permian in the Kitakami mountains.

A large number of corals are also found in the Lower Cretaceous there, and apparently warmer fauna and flora than the present day ones are also known from the Palaeogene and the lower half of the Miocene deposits developed in Northeast Honshu. Since then, the climatic condition of Northeast Honshu seems to have gradually approached the present state, although the existence of certain fluctuation through the Pliocene and Quaternary cannot be denied.

Thus, one cyclic climatic change can be induced in the Kitakami mountains through the geological ages, during which the Upper Viséan to the Lower Permian was the climatic optimum for the tropical fauna.

However, in reality, further detailed examination may be necessary in respect to the palaeoclimatology of the Japanese Islands before the final conclusion is obtained. For example, not only the temperature of sea water, but also humidity estimated from faunal and floral aspects of the land must be taken into consideration in this problem. In addition, the change of depth of water and altitude of land in which deposits were formed is very important for the estimation of the past climatic condition, since the deeper the sea, the colder appeared the fauna, and at the same time the higher the land, the colder appeared the flora.

Further, we know that global climatic changes have really existed in the past, the world-wide ice age and inter-ice age for example. Such being the case, the world-wide fluctuation of climate could certainly have had an influence on the Japanese Islands as on other continents, even if the Japanese Islands were in reality fixed in their geographic position. Change of the currents could also cause the change of temperature in sea water along the coast, even if the land was fixed as at present.

Under such considerations, it may be premature to make a final conclusion on the past climate of the Japanese Islands. Nevertheless, the possibility cannot be denied that a change of latitude of the Japanese Islands really occurred in the geological age as inferred by the palaeomagnetic data. In addition, the change of latitude seems to roughly correspond with the change of palaeoclimatology of the 
Japanese Islands as a whole. Hence, the drifting theory may be also applicable to some extent in the case of the Japanese Islands.

In conclusion, we should like to express our best thanks to Dr. H. Yabe for his kindness to present this paper to the Japan Academy. Thanks are also due to Drs. I. Yokoyama and T. Suzuki for their kind assistance given us during the course of experiments. We are also indebted to Drs. M. G. Rutten, S. Akimoto, and K. Yagi for their fruitful discussions about the palaeomagnetism of the Japanese Palaeozoics.

\section{References}

Dietzel, G. F. L. (1960): Geology and Permian palaeomagnetism of the Merano region, Province of Bolzano, N. Italy. Geol. Ultraiectina, no. 4, p. 11.

Minato, M. (1960): The boundary between the Lower and Upper Carboniferous in Japan. Amer. Jour. Sci., 258, 637.

- (1962): Die Vulkantätigkeit und der Plutonismus im Fernen Osten, Teil 1. Jour. Fac. Sci., Hokkaido Univ., ser. 4, 11(3), 481.

Minato, M. and Fujiwara, Y. (1963): Carboniferous palaeomagnetism of the Kitakami mountains, Northeastern Honshu, Japan. Compte Rendu V International Carb. Congress (in press).

Mori, S. (1961): Animal life (in Japanese). Asakura Co. Ltd., p. 40.

Nagata, T., et al. (1959): Palaeomagnetic studies on Tertiary and Cretaceous rock in Japan. Proc. Japan Acad., 35, 378.

Suzuki, J., and Minato, M. (1958): Gotlandian and Devonian volcanic activities in the Kitakami mountains. Proc. Japan Acad., 34(5), 284.

Yabe, H. (1932): Colonial corals in the geological formations of the Japanese Islands. Proc. Imp. Acad., 8(7), 304. 